\title{
El oficio de platero en la Antequera dieciochesca: tres generaciones de los Gálvez
}

\section{The silversmiths' trade in $18^{\text {th }}$-century Antequera: three generations of the Gálvez family}

\author{
Francisco HIDALGo FERNÁNDEZ \\ Universidad de Málaga \\ frhifer@uma.es
}

Fecha de recepción: 07-04-2018

Fecha de aceptación: 25-10-2018

\section{RESUMEN:}

En este artículo, procedemos a estudiar el traspaso familiar del oficio manufacturero, concretamente el de la platería, a través de tres generaciones de la familia Gálvez a lo largo de la centuria dieciochesca. Para ello, hemos esbozado la situación actual de la historia de la familia con respecto a su interés sobre los sectores artesanales para posteriormente adentrarnos, tras unos datos concretos del linaje, en los talleres y su evolución de forma conjunta con las trayectorias vitales de los individuos, haciendo hincapié en la importancia de las relaciones entre los consanguíneos para el progreso laboral.

PALABRAS CLAVE: Antequera, siglos XVIII, familia, artesanos, plateros,

\section{ABSTRACT:}

In this paper, I study the family transfer of the manufacturing trade, specifically that of silversmiths, through three generations of the Gálvez family throughout the $18^{\text {th }}$ century. To this end, I have outlined the current situation of the family's history of the family with respect to their interest in the artisanal sectors to then consider, after some specific data regarding lineage, the workshops and their evolution together with the lives of the individuals concerned, emphasizing the importance of family to professional and economic progress.

KEY WORDS: Antequera, $18^{\text {th }}$ century, family, artisans, silversmiths 


\section{INTRODUCCIÓN}

Uno de los temas más trascendentales para la investigación durante el período moderno son los espacios de sociabilidad. La débil divisoria que existió entre lo público y privado hace necesario un estudio que albergue un tratamiento cuidadoso y profundamente asentado. Ya para la etapa ilustrada podríamos decir que uno de estos espacios, fundamentales para los estratos con un mayor nivel de formación académica, fueron las tertulias y los cafés ${ }^{1}$, sin embargo, debemos referirnos a la familia y el trabajo manual desarrollado en los talleres como las dos áreas de convivencia más relevantes, ya que fueron compartidas por una amplia mayoría de la población².

En el presente artículo procedemos a analizar la trayectoria laboral de tres plateros radicados en la Antequera del siglo XVIII, todos ellos pertenecientes a un mismo linaje: los Gálvez. El traspaso generacional de la labor artesana a través de las generaciones será analizado de forma conjunta con las modificaciones que se dieron tanto en un nivel microanalítico, es decir, los referidos concretamente al clan, como en el conjunto de la monarquía, fruto de los intereses prerreformistas y reformistas de los Borbones españoles ${ }^{3}$.

Será esta línea política, llevada a cabo por Carlos III y sus ministros, la que marque el principio del fin de las congregaciones gremiales y, por ende, de las relaciones de trabajo existentes hasta el momento. Este hecho supuso la reacción de los artesanos, aunque lejos de ser vistas como actitudes individuales, estos respondieron con una estrategia familiar determinada, pues, a fin de cuentas, la trayectoria vital del individuo moderno quedaba unida a los intereses de sus consanguíneos ${ }^{4}$.

Con ello, el estudio que aquí se introduce presentará el cursus de los plateros Gálvez dentro del mundo artesanal antequerano. No obstante, consideramos además oportuno señalar algunos datos acerca de los cambios producidos en la ciudad andaluza con respecto a la congregación de San Eloy, estudiada, en parte, por Sánchez-Lafuente ${ }^{5}$.

\section{MÁS ALLÁ DEL GREMIO, LAS FAMILIAS ARTESANAS}

Como decimos, el gremio ha sido, de forma tradicional, estudiado en su vertiente institucional u orgánica, las ordenanzas de las congregaciones; los puestos de las mismas; o su papel como grupo de presión sobre el poder municipal han sido los trabajos más numerosos $^{6}$. Sin embargo, y a diferencia de otras actividades económicas, la familia

1 Véase M. A. Pérez Samper, "Espacios y prácticas de sociabilidad en el siglo XVIII: tertulias, refrescos y cafés de Barcelona", Cuadernos de Historia Moderna, 26 (2001), pp. 11-55.

2 Con respecto a las corporaciones gremiales véase J. Colón de Larraeátegui, Tiempos de reforma ilustrada. Informe sobre los gremios de Valladolid, Valladolid, Ayuntamiento, 2008 (ed. L. Amigo Vázquez, M. García Fernández y R. Hernández García); R. Hernández García, "Gremios y corporaciones laborales. Debate historiográficos y estado de la cuestión", Areas, (34 (2015), pp. 7-18.

3 A. Domínguez Ortiz, Sociedad y estado en el siglo XVIII español, Barcelona, Ariel, 1976.

4 Estas estrategias familiares no han de constreñirse solo a los linajes más pudientes o nobles, sino que también se observan en otros más modestos como los jornaleros, pues como expuso García González, hemos de alejarnos de las estructuras simples e inmóviles y adentrarnos en las verdaderamente existentes, donde las situaciones se caracterizaron por su dinamismo. F. García González, Las estrategias de la diferencia. Familia y reproducción social en la Sierra (Alcaraz, siglo XVIII), Madrid, Ministerio de Agricultura, Pesca y Alimentación, 2000, pp. 179-180.

5 R. Sánchez-Lafuente Gémar, "El Colegio-Congregación de plateros de Antequera (1782-1833)", Boletín de Arte, 12 (1991), pp. 317-336.

6 Sobre los estudios jurídicos de las corporaciones destacar J. García Abellán, Organización de los gremios en la Murcia del siglo XVIII y recopilación de ordenanzas, Murcia, Academia Alfonso X el Sabio, 1976; T. de Diego Velasco, Los gremios granadinos a través de sus ordenanzas, Madrid, Universidad Complutense de Madrid, 1986; J. M. Cruz Valdovinos, Los plateros madrileños: estudio histórico-jurídico de su Organización 
artesana ha quedado fuera del interés de muchos historiadores, a pesar de poseer para el siglo XVIII una excelente documentación como es el Catastro del marqués de la Ensenada? .

Sería impreciso, sin embargo, afirmar que el trabajo manufacturero ha sido tratado por la historiografía dejando de lado sus aspectos más sociales, pues, aunque todavía poco numerosas, existen una serie de obras que ahondan en este sentido ${ }^{8}$. No obstante, las metodologías utilizadas en la historia social de la familia quedan lejos de los resortes puestos en prácticas en estas obras. Destacable va a ser la publicada por Moral Roncal sobre los gremios en el Madrid ilustrado, donde si bien no parte de estas concepciones sí introduce datos de gran interés para observar las formas de actuación de los agremiados, así como el papel que tuvieron los miembros de sus familias ${ }^{9}$.

Sin embargo, frente a esta ausencia, la historia de la familia viene reclamando la importancia de los dos espacios de análisis. Cabría mencionar el libro publicado tras la celebración del Congreso celebrado en Murcia en 1994, Familia, Casa y Trabajo, pues como se dejó patente en su prólogo: "La relación entre los tres conceptos se vuelve necesaria para acercarse al conocimiento de la organización social ${ }^{10 " .}$.

El prestigio con que la historia de la familia comenzó el presente siglo auguraba toda una serie de publicaciones destinadas a complejizar el problema combinando múltiples planos de análisis histórico: la familia y el trabajo, entre otros. Sin embargo, debemos mencionar que todavía hoy se acarrea una ausencia en cuanto al tratamiento de los linajes artesanos ${ }^{11}$,

Corporativa, Tomo I, Madrid, Gremio de Joyeros y Plateros de Madrid, 1993.

7 A partir de dicho catastro se podrían estudiar los procesos de movilidad social de los miembros pertenecientes a grupos de trabajo concretos. Véanse A. Guerra Guerra, "Profesionales, obreros y artesanos de Badajoz en 1750: sus ganancias y emolumentos según el Catastro de Ensenada", Revista de estudio extremeños, vol. 27, 3 (1971), pp. 561-582; N. González Barrero, "Los maestros de primeras letras en la provincia de Madrid a través del Catastro de Ensenada", Historia y Memoria de la Educación, 3 (2016), pp. 197-228.

8 J. C. Zofío Llorente, Gremios y artesanos en Madrid, 1550-1650: la sociedad del trabajo en una ciudad cortesana preindustrial, Madrid, Instituto de Estudio Madrileños, 2005; J. A. Nieto Sánchez, Artesanos y mercaderes: una historia social y económica de Madrid, 1450-1850, Madrid, Fundamentos, 2006.

9 A. Moral Roncal, Gremios e llustración en Madrid, (1775-1836), Madrid, Actas, 1998.

10 F. Chacón Jiménez y L. Ferrer i Alós, "Más allá de la familia", en F. Chacón Jiménez y L. Ferrer y Alós (eds.), Familia, casa y trabajo, Murcia, Universidad, 1997, p. 15. En ese mismo volumen destacamos el trabajo sobre los libreros e impresores barceloneses. J. Burgos Rincón, "Gremio, familia artesana y propiedad. Libreros e impresores en la Barcelona del siglo XVIII", en F. Chacón Jiménez y L. Ferrer y Alós (eds.), Familia, casa y trabajo, Murcia, Universidad, 1997, pp. 423-444.

11 El número de estudios sobre las familias artesanas es todavía muy bajo. El porcentaje de estos trabajos entre el año 2000 y 2015 es de apenas un 1'9 \% si tenemos en cuenta las publicaciones correspondientes al Congreso Internacional de Murcia y Albacete y a los trabajos de 2012 y 2014 editados por REFMUR. F. García González y F. J. Crespo Sánchez, "Radiografía de un impulso compartido. La historia de la familia en España e Iberoamérica (2000-2015)", en O. Rey Castelao y P. Cowen (eds.), Familias en el Viejo y el Nuevo Mundo, La Plata, Universidad Nacional de La Plata, 2017, p. 56. Para el tratamiento de los linajes artesanos véase D. A. Frey, "Industrious Households: servival strategies of artisans in a Sothwest German town during the eighteenth an early nineteenth centuries", International Review of Social History, 45 (2000), pp. 115-135; P. Miralles Martínez, Seda, trabajo y sociedad en la Murcia del siglo XVII, Murcia, Universidad, 2000. 
frente a otros como los comerciantes ${ }^{12}$, esclavos ${ }^{13}$, las familias de eclesiásticos ${ }^{14}$ o de las élites de poder ${ }^{15}$.

Pese a todo, la producción anteriormente señalada se configura como la base idónea sobre la que asentar nuevos estudios que ahonden en el problema, llenando este importante vacío historiográfico. Por ello, el artículo pretende presentar la trayectoria de un apellido incidiendo en la relevancia del clan en la formación de un oficio y en la actividad laboral a lo largo de las trayectorias vitales de sus miembros y, además, como instrumento de integración en la sociedad que lo envuelve, en una ubicación especialmente relevante de la región andaluza como es Antequera, y que sirva, a su vez, para paliar el desconocimiento existente de su historia de la sociedad local durante el siglo XVIII.

\section{UNA FAMILIA PLATERA EN TIEMPOS DE CAMBIO}

Antes de entrar de lleno en la cuestión planteada: el traspaso generacional del oficio platero; esbozaremos cómo el linaje llegó a ubicarse en Antequera en las postrimerías del siglo XVII, ayudándonos a comprender el modelo de asentamiento y las pautas de actuación de un grupo social ubicado en una posición limítrofe entre los dos estamentos.

La documentación notarial escriturada por diferentes miembros de la familia señala la idea de una pertenencia al estado noble, concretamente como hijosdalgo, aunque sin ser estos de casa y solar conocido. Uno de los documentos esenciales para comprender el pasado del linaje va a ser la limpieza de sangre datada en 1725 e incorporada al final del testamento de Francisco Miguel de Gálvez Bermudo, siendo este la primera persona del clan establecida en Antequera ${ }^{16}$.

Los distintos testimonios insertos, y que casualmente repiten casi a la perfección lo declarado, nos informan de un suceso tan interesante como común en los tiempos modernos. Naturales de Écija, los padres de Francisco se trasladaron a Osuna, en cuya villa tuvieron al referido hijo en abril de 1673. Tras un tiempo y debido a la escasa capacidad económica de los progenitores, estos dejaron al infante, antes de su vuelta a la ciudad de donde eran

12 P. Fernández Pérez y J. C. Sola-Corbacho, "Familia y Comerciantes en la España del Antiguo Régimen", en F. Chacón Jiménez y J. Hernández Franco (eds.), Espacios sociales, universos familiares. La familia en la historiografía española, Murcia, Universidad de Murcia, 2007, pp. 177-191; J. Mallo, "Emociones, honra y familia. Comerciantes españoles a finales del siglo XVIII", en O. Rey Castelao y P. Cowen (eds.), Familias en el Viejo y el Nuevo Mundo, La Plata, Universidad Nacional de La Plata, 2017, pp. 367-385.

13 A. J. Morgado García, "La vida familiar de los esclavos en el Cádiz de la modernidad (1600-1750)", Trocadero: revista de historia moderna y contemporánea, 24 (2012), pp. 67-81; A. J. Morgado García, "El ciclo vital de los esclavos en el Cádiz de la modernidad", Revista de historia moderna: Anales de la Universidad de Alicante, 34 (2016), pp. 297-315.

14 A. Irigoyen López, "Un obispado para la familia: Francisco Verdín Molina, prelado de Guadalajara y Valladolid en la segunda mitad del siglo XVII", Historia mexicana, vol. 58, 2 (2008), pp. 557-594; A. Irigoyen López, "Bajo el manto de la Iglesia. Clero y familia en España durante la Edad Moderna", en F. Chacón Jiménez y J. Hernández Franco (eds.), Espacios sociales, universos familiares. La familia en la historiografía española, Murcia, Universidad de Murcia, 2007, pp. 245-269.

15 M. Hernández Benítez, A la sombra de la Corona. Poder local y oligarquía urbana (Madrid, 1606-1808), Madrid, Siglo XXI, 1995; J. Hernández Franco y S. Molina Puche, "La sangre de la familia y su proceso socioinstitucional. Siglos XVI-XVII" en F. Chacón Jiménez y J. Bestard Camps (dirs.), Familias. Historia de la sociedad española (del final de la Edad Media a nuestros días), Madrid, Cátedra, 2011, pp. 113-156.

16 El documento de limpieza de sangre fue realizado tras la petición de los dos hijos de Francisco Miguel. Extraña es su ubicación al final de una escritura testamentaria. Además, las informaciones proporcionadas en dicho documento tan sólo hacen referencia a la línea paterna, por lo que consideramos que no se trata del original, pese a que otras escrituras notariales de años sucesivos nos remiten a él. Archivo Histórico Municipal de Antequera (AHMA), Fondo de Protocolos Notariales, escribanía de Bernardo José de Lasarte, leg. 262, fol. 166r-204v. 
oriundos $^{17}$, en casa de María Juárez de Figueroa, una mujer viuda, que, consideramos por lo testimoniado, también anciana ${ }^{18}$. El objetivo de la acción fue que María dejara como único y universal heredero a Francisco, pues era "rica y sin tener heredero forzoso ${ }^{19 ",}$ al mismo tiempo que el niño ofreciera cuidados y compañía a la testadora ${ }^{20}$.

La muerte de María Juárez, 8 ó 9 años después, puso fin a la convivencia de ambos, forzando el traslado de Francisco, tras la consecución de la herencia, a la ciudad de Antequera. Este movimiento ha de explicarse mediante la existencia de unas redes sociales entre ambas localidades, aunque desconocemos los nombres que la integraron. Hemos de suponer que la ligazón fue con el linaje Almoguera, produciéndose a finales de la década de los 80 el matrimonio entre Francisco Miguel de Gálvez Bermudo y María Francisca de Almoguera y Rojas ${ }^{21}$.

De este matrimonio nacerán dos hijos: Francisco y Alonso de Gálvez Almoguera, en 1690 y 1693 respectivamente ${ }^{22}$. Siguiendo la línea genealógica del segundo, fruto de su dedicación artesanal, frente a la formación como galeno de su hermano y la integración de sus descendientes en los resortes del poder local antequerano.

Antes de finalizar este sucinto recorrido por los primeros años de los Gálvez en su nuevo emplazamiento, haremos mención de su condición dentro de los esquemas sociales de la Edad Moderna. El asentamiento, vía matrimonial, de Francisco Miguel de Gálvez Bermudo, vino a coincidir con unos momentos convulsos para la Monarquía Católica. La muerte de Carlos II en 1700 abrió la puerta al conflicto sucesorio que disputaría el trono español. Este panorama fue a su vez un momento ideal para la mejora social de muchos individuos que supieron beneficiarse de lo ocurrido.

Una declaración testamentaria datada en 1750, perteneciente al segundogénito, indica la vinculación de su padre y su abuelo materno, Salvador de Almoguera, con el estrato hidalgo de la ciudad, pues "en el Archivo que esta dicha Ciudad de Antequera tiene, en sus libros y padrón que se hizo en el año de mil setecientos y seis, se hallen empadronados por nobles ${ }^{23}$. Este padrón al que hace referencia, realizado al calor de las dificultades atravesadas por el bando borbónico ante el avance austracista ${ }^{24}$, no se conservó para la

17 No se arroja información sobre cuánto tiempo estuvieron los padres en Osuna, aunque suponemos que el traslado a Écija se produjo cuando Francisco era apenas un niño.

18 A. Marchant Rivera, "El prohijamiento, la tutela y la carta de aprendiz: instrumentos para una historia de la situación del menor en Málaga durante la primera mitad del siglo XVI", en J. J. Bravo Caro y J. Sanz Sampelayo (coord.), Población y grupos sociales en el Antiguo Régimen, vol. 2, Málaga, Área de Historia Moderna de la Universidad de Málaga, 2009, pp. 943-956.

19 AHMA, Fondo de Protocolos notariales, escribanía de Bernardo José de Lasarte, leg 262, fol. 167r.

20 F. García González, "Vejez, viudedad y soledad rural. Viudas, hogares y prácticas familiares en la España centro-meridional del siglo XVIII", Studia historica. Historia moderna, vol. 38, 2 (2016), pp. 287-324.

21 Se conoce el nacimiento del primer hijo tenido en matrimonio, Francisco de Gálvez Almoguera, en el año 1690, por lo que consideramos que el matrimonio se tuvo que producir alrededor de 1689. Esta fecha supone que el casamiento se produjo teniendo el novio apenas 16-17 años, edad considerablemente menor que podría explicar las ansias de asentamiento del joven. F. García González, "Las estructuras familiares y su relación con los recursos humanos y económicos", en F. Chacón y J. Bestard (dirs.), Familias. Historia de la sociedad española (del final de la Edad Media a nuestros días), Madrid, Cátedra, 2011, pp. 172-174.

22 AHMA, Fondo de Protocolos Notariales, escribanía de Bernardo José de Lasarte, leg. 262, fol. 166r-204v. Tenemos constancia del bautismo de otros dos vástagos entre la década de los 90 e inicios del siglo XVIII, sin embargo, la inexistencia de referencias a ellos en los documentos testamentarios de sus padres nos indica que ambos murieron en edad pupilar.

23 AHMA, Fondo de Protocolos Notariales, escribanía de Francisco Jiménez Loaiza, leg. 2488, fol. 621v.

24 F. J. Gutiérrez Nieto y P. Ybañez Worboys, "El llamamiento a la nobleza de las «dos Andalucías» de 1706", Revista de Historia Moderna, 25 (2007), pp. 53-87. 
ciudad de Antequera, sin embargo, la documentación indirecta nos indica que efectivamente ambos nombres se inscribieron en él por haber sido "pronto con sus armas y caballo25".

Por tanto, aun desconociendo los orígenes ecijanos de la familia Gálvez, y aunque se indica que también allí disfrutaron de una condición hidalga, es interesante observar cómo la promoción social, desde una posición nada ventajosa, se basó en unos bienes no pertenecientes al linaje, como fueron los de María Juárez, y a una calidad noble derivada de las vicisitudes atravesadas por la monarquía, ya que involucrándose en este sector privilegiado supieron escalar a otras posiciones más elevadas, algo que se podría observar mejor en las trayectorias de la línea iniciada con su primogénito, aunque también con la de su segundo hijo, Alonso, que pese a estar ligado con la artesanía platera poseyó una hacienda doméstica nada desdeñable.

Destacar, por último, un segundo matrimonio tras la muerte de la primera mujer de Francisco Miguel, María Francisca de Almoguera y Rojas en marzo de $1709^{26}$. Este segundo casamiento con María Rosa Rivas ${ }^{27}$, que se mantuvo hasta la muerte del cónyuge en 1740 , dejó entre otros hijos a Juan Anselmo Gálvez y Rivas, nacido en 1714, y cuya trayectoria laboral estuvo pareja también con la artesanía platera, observándose en ello y de forma clara, la estrategia de un linaje vinculado al mundo manufacturero y que tan sólo congració al primogénito con una formación universitaria, básica para una futura promoción por parte de sus descendientes.

\subsection{El traspaso del oficio platero a través de las generaciones}

Como hemos planteado al inicio, pasamos ahora a exponer la actividad laboral de tres miembros del linaje Gálvez: Francisco Miguel de Gálvez Bermudo, Alonso de Gálvez Almoguera y, el hijo de este último, Félix de Gálvez Sánchez ${ }^{28}$. Una actividad, la de los tres individuos, que se desarrolló íntegramente en la ciudad de Antequera desde inicios del siglo XVIII hasta los primeros años del XIX, momento en el que se pierde el rastro documental del último de los nombres mencionados ${ }^{29}$.

25 Archivo Histórico Nacional (AHN), Estado-Carlos III, Exp. 1487, fol. 32r. El documento data de 1815 es la prueba genealógica de Francisco Javier de Gálvez y Velasco realizada para su entrada en la Orden de Carlos III.

26 AHMA, Fondo Parroquial, Lb. 546, fol. 45r.

27 La unión con la familia Rivas precisa un estudio más profundo, aunque apunta a priori una estrategia matrimonial común entre Salvador de Almoguera tras quedar viudo y su yerno, Francisco Miguel de Gálvez, enlace entre estos dos apellidos que se repetirá en 1715 mediante la unión entre Alonso de Gálvez Almoguera y Teresa Correa Rivas.

28 C. Alexandre y F. J. Ruggiu, "La circulación de los oficios en Charleville. Familia y trabajo en los siglos XVIII y XIX", Revista de Historia Moderna. Anales de la Universidad de Alicante, 34 (2016), pp. 239-256.

29 Otras familias de plateros han sido tratadas, aunque con una base puramente genealógica, sin estudiar las trayectorias vitales de cada uno de sus integrantes, en cierta medida por tratarse de estudios derivados de la Historia del Arte. Véanse M. V. Herraéz Ortega, "Los Bello, platero de Sahagún, y las cruces procesionales de Vallecillo y Joarilla de las Matas (León)", en J. Rivas Carmona (coord.), Estudios de Platería: San Eloy, vol. 2, Murcia, Universidad, 2002, pp. 183-194; J. M. Cruz Valdovinos y P. Nieva Soto, "Los Morenos, una familia de plateros madrileña en el Antiguo Régimen", Anales del Instituto de Estudios Madrileños, 44 (2004), pp. 331-358; F. J. Fernández Guirao, "Los Laborda, una familia de plateros entre los siglos XVIII-XIX", CLAVIS, 9 (2016), pp. 77-102. 
Figura 1. Genealogía de los tres plateros antequeranos

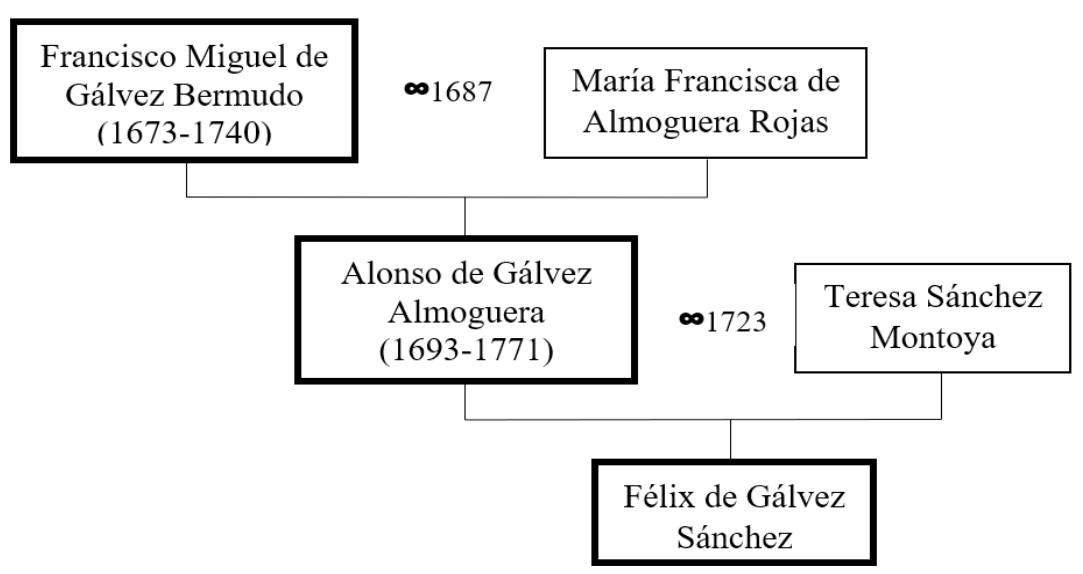

Los orígenes de la dedicación platera del linaje tratado hemos de localizarlo en la figura de Francisco Miguel de Gálvez, pues no se ha encontrado reminiscencia alguna sobre la dedicación de su padre o, incluso, su suegro; en definitiva, alguna relación que lo vinculara con tal oficio.

Sin embargo, el principal problema que nos encontramos a la hora de ahondar en su actividad manufacturera es la ausencia de referencias en la documentación, pues a diferencia de los dos casos que serán expuestos posteriormente, las escrituras no proporcionan dato alguno sobre el asunto, tan sólo en años mucho más avanzados de la centuria dieciochesca se puede leer que Francisco Miguel de Gálvez tuvo esta filiación profesional ${ }^{30}$.

Asimismo, la bibliografía utilizada sí hace mención a dicho platero, concretamente Sánchez-Lafuente le adjudica la autoría de una naveta de la iglesia de Santiago, vinculándolo con la marca personal GAL/BES ${ }^{31}$. Sin embargo, esta pieza está fechada en 1743, mientras que su defunción había ocurrido tres años antes, el 24 de agosto de $1740^{32}$. Ante esta situación, parece factible que poseyera un taller, aunque no ejerciera como trabajador del mismo, hecho que viene a coincidir con una condición noble basada más en la apariencia que en la realidad ${ }^{33}$, máximo si tenemos en cuenta el proceso de ennoblecimiento iniciado al calor de la Guerra de Sucesión que hemos señalado anteriormente.

De hecho, lo único perceptible en sus escrituras es la adquisición o venta de inmuebles y terrenos, señalando la compra de una casa principal en calle de la Calzada por un precio de ocho mil reales o la venta de un olivar en la villa de Osuna, suponemos que llegado a su poder tras la herencia recibida por muerte de María Juárez ${ }^{34}$.

El segundo de los hijos de este, Alonso de Gálvez Almoguera, nos ofrece un mayor volumen de documentación con referencias al desarrollo del oficio de platero, procedente en su mayoría de las escrituras notariales. Nacido en 1693, contrajo primeras nupcias

30 AHMA, Fondo de Hermandades y Cofradías, C. 32, carp. 5, fol. 8r.

31 R. Sánchez-Lafuente Gémar, El Arte de Platería en Málaga, 1550-1800, Málaga, Universidad, 1997, p. 324.

32 AHMA, Fondo Parroquial, Lb. 540, fol. 109r.

33 Como señala Moral Roncal, el individuo asumió toda una serie de caracteres distintivos para manifestar un lugar más elevado dentro de la comunidad como, por ejemplo, la vestimenta. Bajo este mismo prisma, y si la economía lo permitió, los oficios manufactureros quedaron relegados por la nobleza, por lo que desligarse de ella sería un camino más en la preeminencia social. A. M. Moral Roncal, "Honor, vileza y honra de los oficios mecánicos en el siglo XVIII", Baetica, 18 (1996), pp. 379-380.

34 AHMA, Fondo de Protocolos Notariales, leg. 262, fol. 163r-163v. 
en 1715, un matrimonio que finalizaría con la defunción de su esposa en 1719, sin dejar descendencia alguna ${ }^{35}$. Años después, en 1723 enlazaría de nuevo con Teresa Sánchez Montoya, teniendo de ella el que iba a ser su primogénito y heredero del oficio, sin embargo, dos años después su segunda esposa también encontraba la muerte ${ }^{36}$. Finalmente, en 1727 se producía el casamiento con Juana de Acedo García Orbaneja ${ }^{37}$, matrimonio que, dejando una numerosa descendencia, se disolvería ya en 1771 con la defunción de Alonso de Gálvez ${ }^{38}$.

Va a ser precisamente de este último matrimonio cuando comenzamos a vislumbrar una serie de objetos que nos señalan una dedicación concreta, la del trabajo de la plata. En el capital otorgado de Alonso se incorporó todo un arsenal de objetos orfebres como "unas tenazas de tirar hilo de plata", "una espada toledana con puño de plata", o "diferentes alhajas de obra fina de esmeraldas y diamantes engarzados en oro ${ }^{39 " . ~ A ~ e s t e ~ c a p i t a l, ~ o t o r g a d o ~ e n ~}$ 1727, le siguió su testamento en 1750 donde dejó constancia de algunas piezas realizadas en su taller y que quedan explicadas para una posible identificación:

Declaro yo el otorgante que por el testamento que otorgué en el año de mil setecientos veinte y nueve, ante dicho Miguel de Talavera, mandé a la milagrosa imagen de nuestra Señora del Rosario, que se venera en dicho convento del Señor Santo Domingo de esta ciudad, cuatro láminas con sus molduras doradas de talle, la una con un pastorcito, otra con un San Juan, otra con Santo Domingo, y otra con una San Francisco de Asís [...] y así mismo en el año de mil setecientos cuarenta y cuatro di y entregué a don Ricardo Estrange, Hermano Mayor que fue de dicha cofradía de Nuestra Señora del Rosario, una paloma de plata cincelada con su rótulo en el pecho que dice, la dio Alonso de Gálvez, con peso de ocho onzas y diez adarmes ${ }^{40}$.

Tres años más tarde, y al calor de la elaboración del Catastro del marqués de la Ensenada, se introduce a Alonso de Gálvez Almoguera como uno de los maestros plateros de Antequera, de cuyo taller obtiene un beneficio anual de 4.380 reales, haciendo constar, además, que tiene un hijo del mismo arte. Más adelante, en otro apartado reservado a los plateros, afirma que Alonso, "maestro platero que no trabaja"1", utilizada para el jornal de su hijo Félix Gálvez 1.080 reales $^{42}$.

La aclaración "maestro platero que no trabaja", ha de ser explicada por dos motivos fundamentales. El primero vendría dado por su propio ciclo vital, recordemos que, nacido en las postrimerías del siglo XVII, Alonso tendría en 1753 la edad de 60 años, por lo que las capacidades para seguir con el desarrollo de la actividad artesanal se verían reducidas ${ }^{43}$.

35 AHMA, Fondo Parroquial, Lb. 547, fol. 138r.

36 AHMA, Fondo Parroquial, Lb. 514, fol. 243v.; AHMA, Fondo Parroquial, Lb. 547, fol. 260r.

37 AHMA, Fondo Parroquial, Lb. 55, fol. 8r.

38 AHMA, Fondo Parroquial, Lb. 551, fol. 216r. Sobre las nuevas nupcias véanse M. Birriel Salcedo, "El cónyuge supérstite en el derecho hispano", Chronica Nova, 34 (2008), pp. 13-44.

39 AHMA, Fondo de Protocolos Notariales, escribanía de Miguel Francisco de Talavera, leg. 2561, fols. 200r-205v.

40 AHMA, Fondo de Protocolos Notariales, escribanía de Francisco Jiménez Loaiza, leg. 2488, fols. 620v-621r.

41 AHMA, Fondo Municipal, Catastro de Ensenada, Respuestas Particulares, Lb. 1997, fol. 420v.

42 Ibidem.

43 La vejez ha de ser entendida como un concepto cultural más que biológico. Si para la mujer esta etapa vital comenzaba a partir del climaterio, es decir, por una ausencia en la capacidad reproductora, para el hombre llegaba en el momento que no se pudiera ejercer las actividades económicas pertinentes. M. Ortega López, "Las edades de las mujeres", en I. Morant (dirs.), Historia de las mujeres en España y América Latina, 
Este aspecto unido a una solvencia en la economía doméstica ${ }^{44}$ y a la existencia de un hijo, recordemos primogénito, que desarrollará el arte, pudo influir en una retirada del trabajo manual, aunque manteniendo la administración del taller.

Más tarde, la que fuera su tercera mujer, Juana de Acedo, escrituraba un testamento como viuda en 1789 en el que declaraba que "desde hace cinco años antes que enviudé estuvimos y estoy a expensas de los referidos mis hijos por no tener bienes de consideración ${ }^{45 " . ~ E s t e ~ d e s c e n s o ~ s e n ̃ a l a d o ~ e n ~ l a ~ h a c i e n d a ~ f a m i l i a r ~ p u d o ~ s e r ~ n o ~ m a ́ s ~ q u e ~ u n ~}$ intento de ocultación de bienes o, por otro lado, un verdadero declive, que no ausencia, en el capital familiar producto de la total retirada de Alonso como regente del taller en sus últimos años de vida. Esta última circunstancia dio como resultado la necesidad de desplegar una ayuda intergeneracional básica para el mantenimiento de los ancianos durante la Edad Moderna ${ }^{46}$.

Fue, sin lugar a duda, el hijo de Alonso, Félix de Gálvez la figura que mayor interés albergue, no tanto a nivel familiar, pues escasos conocimientos tenemos sobre esta materia, sino en el terreno laboral ${ }^{47}$, debido a su trayectoria durante los años de vida de la Congregación de Plateros de San Eloy en Antequera ${ }^{48}$.

La primera noticia acerca de su actividad como platero va a ser la mencionada arriba en el Catastro de Ensenada, con respecto al trabajo desempeñado en el taller de su progenitor. De hecho, tres años antes en el testamento de Alonso se incorporan como parte de la herencia "las herramientas del uso del arte de platería que yo tengo ${ }^{49 "}$. A partir de este momento, la ausencia de rastro documental dejado por Félix hace imposible reconstruir parte de su vida hasta años muy avanzados del siglo XVIII, momento en el que nazca la congregación antequerana ${ }^{50}$.

Fue precisamente en estas últimas décadas de la centuria cuando se produzca con mayor virulencia una situación de debate con respecto al papel desempeñado por los gremios en el desarrollo del Estado ${ }^{51}$. En este ambiente se promulgaron para la platería española unas ordenanzas generales en marzo de 1771 que, entre otras cuestiones, ordenaba la entrada obligada de los artífices en una congregación local o, ante su inexistencia, lo más

vol. 2, Madrid, Cátedra, 2005, pp. 317-350.

44 Esta solvencia no solo es percibida por las cuantías indicadas en los documentos como capitales o dotes, sino que el propio catastro posiciona a Alonso de Gálvez como uno de los maestros plateros que mayor beneficio extrae de su actividad manufacturera, tan sólo igualado por otro maestro del arte, Antonio de Montes.

45 AHMA, Fondo de Protocolos Notariales, escribanía de Antonio María de Talavera, leg. 2507, fol. 555v.

46 F. García González, "Vejez, viudedad..., pp. 313-318; S. Narotzky, "La renta del afecto: ideología y reproducción en el cuidado de los viejos", en J. Prat y Carós, I. Moreno Navarro, U. Martínez Vega y J. Contreras Hernández (coords.), Antropología de los pueblos de España, Madrid, Taurus, 1991, pp. 464-474.

47 Un recorrido sobre los distintos plateros antequeranos de finales del siglo XVIII e inicios del XIX se encuentra en A. Llordén, "Noticas históricas de los maestros plateros antequeranos, siglos XVIII-XIX", Jábega, (8 (1974), pp. 81-92.

48 Véase R. Sánchez-Lafuente Gémar, "El Colegio-congregación de plateros de Antequera (1782-1833)", Boletín de Arte, 12 (1991), pp. 317-336.

49 AHMA, Fondo de Protocolos Notariales, escribanía de Francisco Jiménez Loaiza, leg. 2488, fol. 623r.

50 Los intentos de la Congregación de Plateros de Málaga de absorber a los artífices antequeranos dieron precisamente como resultado la creación de la institución antequerana. J. Escalante Jiménez, Miscelánea Histórica de Antequera, Antequera, Fundación Municipal de Cultura, pp. 124-127.

51 Véanse, por ejemplo, los escritos del momento de Gaspar Melchor de Jovellanos, Informe sobre el libro ejercicio de las artes, o el Discurso política económico sobre la influencia de los gremios en el Estado de Antonio de Capmany y Montpalau. A. González Enciso, "los gremios y el crecimiento económico", Memoria y Civilización, 1 (1998), pp. 111-137. 
cercana posible, y que, en última instancia perseguía erradicar con la costumbre de ejercer como maestro platero sin estar aprobado para ello ${ }^{52}$ :

Ninguno de aquí adelante podrá ejercer este arte, ni poner tienda u obrador de las cosas pertenecientes a él en España, sin que además de la cualidad de maestro aprobado, tenga la de estar admitido e incorporado en la Congregación o Colegio de Plateros, donde haya de residir con casa poblada [...] se ordena que desde la publicación de esta Real Cédula en adelante, ninguno, sin embargo de estar aprobado para el uso del Arte de Platería pueda abrir tienda, ni establecer su ejercicio en alguna ciudad, villa, ni lugar en estos reinos, sin que primero conste estar legítimamente admitido e incorporado en la Congregación ${ }^{53}$.

De hecho, fue precisamente este el caso de los maestros plateros antequeranos. Así, si en 1753 Félix de Gálvez aparecía ya como maestro en el obrador de su padre, en 1777 se presentaba al examen contando ya con unos 50 años ${ }^{54}$. Pasados por examen, el siguiente escalón fue la creación de una congregación propia de la ciudad de Antequera que nació finalmente en 1782. Fue dentro de ella y en cargos de máxima responsabilidad donde la familia Gálvez tuvo mayor presencia ${ }^{55}$, pues en el caso de Félix llegaría a ocupar el cargo de Hermano Mayor entre 1784-1787, 1791-1792 y 1795 y 1799 aproximadamente ${ }^{56}$.

Como decimos, pese a la importancia institucional o artísticas de sus obras, algunas de las cuales llegaron incluso a Madrid ${ }^{57}$, existen grandes problemas para rastrear los pasos de la vida personal de Félix de Gálvez, especialmente durante sus últimos años de vida, hecho que se explica por el abandono de la ciudad de Antequera. No obstante, no consideramos factible dicha posibilidad, pues supondría un movimiento migratorio a unas edades muy avanzadas.

Como fuere, Félix de Gálvez tuvo que morir antes de la desaparición de la congregación antequerana, acaecida en 1833, siendo uno de los plateros locales más relevantes no sólo por su posicionamiento en la institución, sino por el capital económico que amasó y la calidad que sus obras tuvieron. Aunque no debemos olvidar, que dicha distinción no debe ser desprendida de la trayectoria familiar anterior y muy especialmente del trabajo desempeñado en el taller de su padre. Asimismo, el estudio de otros personajes de la familia Gálvez reflejan el recuerdo constante de su calidad como hidalgos, este hecho, que tuvo que ser compartido por el propio Félix, ha de ser mencionado conjunto a la Real Cédula promulgada por Carlos III en 1783, en la que declaraba el trabajo manual como un ejercicio "honesto y honrado; y que el uso de ellos no envilece la familia, ni la persona que los ejerce ${ }^{58 "}$.

52 R. Sánchez-Lafuente Gémar, "La platería de Málaga en el siglo XVIII", en J. Rivas Carmona (coord.), Estudios de Platería: San Eloy, vol. 1, Murcia, Universidad, 2001, p. 251.

53 Real Despacho de ordenanzas aprobadas por su magestad a consulta de la Junta General de Comercio y Moneda, para todas las platerías de estos reynos, Málaga, oficina de Antonio Fernández Quincozes, 1831, pp. 4-5.

54 R. Sánchez-Lafuente Gémar, El Arte..., p. 258.

55 Hemos mencionada aquí la vinculación de Félix de Gálvez Sánchez con la platería antequerana, sin embargo, no fue el único miembro de la familia que la desarrolló, también cabría mencionar a Agustín de Gálvez Acedo, hijo de Alonso de Gálvez con su tercera mujer, Juana de Acedo.

56 Si bien las fechas indicadas son proporcionadas por el historiador del arte Sánchez-Lafuente, el padre Llordén afirma que Félix ocupó el cargo de manera continuada desde 1797 a 1802. A. Llordén, "Noticias históricas..., p. 87.

57 J. M. Cruz Valdovinos, Catálogo de platería, Madrid, Ministerio de Cultura, 1982, p. 148.

58 Real Cédula de S. M. y señores del Consejo, Madrid, Imprenta de Don Pedro Marín, 1783; J. Guillamón 


\subsection{Desde su puericia empezó a aprender el Arte: José de Gálvez y Calo}

Tras ver el proceso de transmisión del oficio platero en las tres generaciones marcadas, queremos hacer una postrimera mención a un miembro que aún perteneciente a la familia, entendida esta en su sentido más amplio, no pertenece a la línea de los casos expuestos anteriormente ${ }^{59}$.

Retrotrayéndonos, de nuevo, a la figura de Francisco Miguel de Gálvez Bermudo, vimos cómo tras la muerte de su primera mujer contraería nuevas nupcias con María Rosa Rivas y Carrera, matrimonio que perduraría hasta la defunción del platero en 1740, dejando entre otros hijos a Juan Anselmo de Gálvez y Rivas. Este último, que seguirá también con el oficio tradicional, queda inscrito en el Catastro de Ensenada como maestro platero, cuya familia se compone de una mujer, un hijo menor y una sirvienta, obteniendo un beneficio anual de 1.080 reales $^{60}$.

Juan de Gálvez contrajo matrimonio en 1747 con Isabel de Calo ${ }^{61}$, naciendo, entre uno de sus vástagos, su hijo José en una fecha comprendida entre 1748 y 1756, año en el que la madre murió62. Va a ser este quien en 1785 solicite a la Congregación de Plateros de San Eloy "lo matriculen de oficial en el libro que para ello tiene la congregación que en ello recibirá merced ${ }^{63 "}$. Este caso nos permitirá no sólo seguir viendo el mantenimiento del oficio por los integrantes de los Gálvez, sino observar cómo los lazos sanguíneos se convirtieron en un instrumento esencial para la entrada en las congregaciones gremiales, pues como referenciamos más arriba van a ser precisamente los integrantes familiares los que ostenten los puestos de máxima responsabilidad.

Figura 2. Fragmento del árbol genealógico de la familia Gálvez

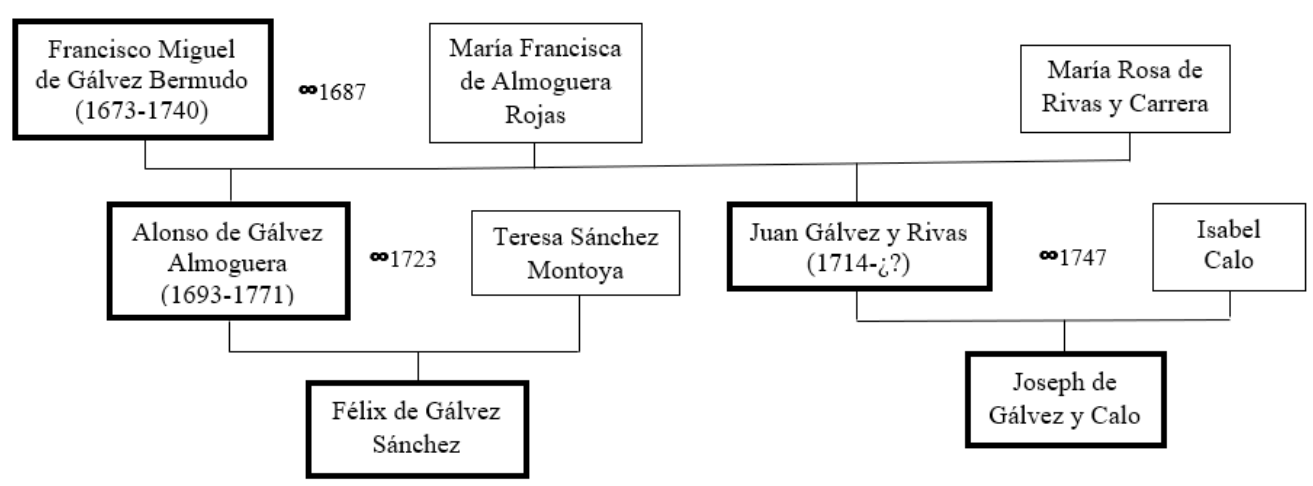

Fue, de hecho, el propio solicitante el que recurrió a su propia familia como elemento meritorio, resultando más fácil así el desenlace positivo de la petición. En el documento, del 14 de enero de 1785, asegura que:

Álvarez, Honor y honra en la España del siglo XVIII, Madrid, Departamento de Historia Moderna de la Universidad Complutense de Madrid, 1981.

59 F. Chacón Jiménez, "Familia, casa y hogar. Una aproximación a la definición y realidad de la organización social española (siglos XVIII-XIX)", en F. Chacón Jiménez y J. Hernández Franco (eds.), Espacios sociales, universos familiares. La familia en la historiografía española, Murcia, Universidad, 2007, pp. 51-68.

60 AHMA, Fondo Municipal, Catastro de Ensenada, Respuestas Particulares, Lb. 1997, fol. 421v.

61 AHMA, Fondo Parroquial, Lb. 349, fol. 178v.

62 AHMA, Fondo Parroquial, Lb. 551, fol. 183r.

63 AHMA, Fondo de Hermandades y Cofradías, C. 32, carp. 5, fol. 8r. 
Dicho mi padre individuo que fue de dicha congregación como así mismo mi abuelo, maestro de dicho arte en esta ciudad [...] y hablando con el respeto debido dice que desde el tiempo de su purilidad (sic) ha estado con dicho su padre aprendiendo dicho arte y por su muerte ahora tiempo de dos años ha estado en los obradores de sus primero don Agustín y don Félix de Gálvez, artífices del Colegio y de presente se haya en el de dicho don Félix como también con la edad de veinte y cuatro años por el cual tiempo tener cumplido los seis años de aprendido [que] se previene en las reales ordenanzas ${ }^{64}$.

En este pequeño fragmento queda patente la plena vinculación de la familia con el oficio de platería, lo que ofreció al joven la posibilidad de formarse en un primer momento con su padre y, tras la muerte del mismo, con otros miembros, destacando a Félix de Gálvez, que recordemos fue Hermano Mayor de la congregación en los momentos precisos de esta petición, 1784-1787. Por otra parte, Agustín de Gálvez, en cuyo taller tuvo formación en solicitante, ejercía como secretario de la institución, observando su rúbrica en los documentos que forman el expediente de la petición. Este mismo, ocuparía el cargo de Hermano Mayor a partir 1787, ejerciéndolo durante dos años ${ }^{65}$.

En otro orden de cosas, interesante es el apunte acerca de sus años como aprendiz en los talleres de sus consanguíneos, atestiguando la duración de seis años, requerida por las ordenanzas ${ }^{66}$. Durante este período formativo los aprendices debían formarse en el conocimiento de los metales, aleaciones, herramientas a utilizar o el dominio del dibujo ${ }^{67}$.

Volviendo a la solicitud de José de Gálvez y Calo, la contestación de la misma vino de mano de Agustín de Gálvez como secretario de la corporación, en la cual se daba a conocer que mediante la junta celebrada el 17 de ese mismo mes de enero, se nombraba a José Sánchez y Antonio Montes para que informasen. Días después, los mencionados verificaban los datos proporcionados por José de Gálvez, declarando, además, que sus antepasados "no han sido procesados por el Santo Oficio de la Inquisición, y que son tenidos por cristianos viejos, y reputados por familia honorífica de esta ciudad ${ }^{68 "} \mathrm{y}$, por tanto, aceptando su entrada en la Congregación de San Eloy. La sangre seguía constituyendo a fines de la modernidad un elemento esencial de validez social y la familia que la albergaba la célula perfecta de integración y relación con la comunidad.

64 AHMA, Fondo de Hermandades y Congregaciones, C. 32, carp. 5, fo. 8r.

65 AHMA, Fondo de Hermandades y Congregaciones, C. 32, carp. 4, fol. 1r.

66 Este tiempo de aprendizaje queda establecido en las ordenanzas de 1771, concretamente en el título IV, capítulos V: "De los exámenes y aprobaciones de maestros", en Real Despacho de Ordenanzas..., p. 36. La duración del aprendizaje varió según el oficio, aunque generalmente se estipuló entre 4 y 6 años. Con respecto a esto Hernández López señala para el caso albaceteño que el 61 \% de los aprendices dedicaron a su formación entre 6 y 7 años, mientras que Zofío Llorente para el Madrid del Antiguo Régimen ofrece una cifra más rebajada. Pese a ello, la media para el oficio de platería, que precisaba una mayor formación, fue de 5 a 6 años. C. Hernández López, "Trabajo y curso de vida. Los artesanos de Albacete (1636-1792)", en J. F. Henarejos López y A. Irigoyen López (eds.), Escenarios de familia: trayectorias, estrategias y pautas culturales, siglo XVI-XX, Murcia, Universidad, 2017, p. 260.

67 C. Benavides Murillo, "Reflexiones sobre la formación y función social de los artesanos de Cartago en el siglo XVIII", Revista Estudios, 18-19 (2004-2005), p. 27; M. D. Barroso Vázquez, "Los plateros portuenses: análisis de su organización corporativa", Revista de Historia de El Puerto, 4 (1990), p. 59. Sobre el aprendizaje gremial véase J. A. Nieto Sánchez y J. C. Zofío Llorente, "Los gremios de Madrid durante la Edad Moderna: una revisión", Áreas, 34 (2015), pp. 47-61.

68 AHMA, Fondo de Hermandades y Cofradías, C. 32, carp. 5, fol. 8v-9r. 


\section{CONCLUSIONES}

Durante el desarrollo del trabajo hemos hecho un recorrido por las trayectorias vitales de algunos de los miembros del linaje Gálvez haciendo hincapié en la vinculación familia y trabajo, al calor también de la evolución ideológica del siglo XVIII. Partiendo de la figura de Francisco Miguel de Gálvez que, beneficiado de un capital llegado a él mediante una herencia indirecta, así como a los avatares vividos por la monarquía hispánica a principios del setecientos, pudo incorporarse entre el grupo privilegiado de la localidad de Antequera mediante su inscripción en el padrón de 1706.

Por otra parte, esta nueva posición le ofreció la posibilidad de ostentar un taller platero sin que se conozca su actividad personal, pues como vimos la única obra catalogada con su marca personal está datada en unas fechas posteriores a su defunción. Asimismo, a inicios del siglo XIX, una prueba genealógica indica que ninguno de los antepasados Gálvez había ejercido trabajos manuales, hecho que corrobora el mantenimiento ideológico de una nobleza que, en parte, se fundamenta por su lejanía a la labor manufacturera.

Al mismo tiempo, el objetivo de la estrategia familiar no fue en ningún momento el mantenimiento de dicho trabajo, pues al primogénito le deparó un futuro alejado de la vida artesanal, en pro de introducirse en la red de la oligarquía local, siendo el trampolín para dicho recorrido la formación universitaria. Por tanto, fue el segundogénito el que mantuvo la dedicación platera conociendo del mismo algunas piezas como las que él introdujo en su documento testamentario. En su caso, se pudo observar el proceso evolutivo del trabajo junto con el ciclo vital. La vejez, entendida como el momento de desaparición de las capacidades de productividad económica, le supuso en un primer momento el abandono del ejercicio manual, aunque manteniendo la regencia de su propio taller, cuya elaboración de piezas recayó sobre su hijo Félix. Este alejamiento parcial fue seguido de la desvinculación total del taller en fechas más avanzadas, hecho que supuso la retirada de los beneficios, lo que produjo el inicio de una ayuda intergeneracional por parte de sus hijos.

La tercera generación, personificada en la figura de Félix de Gálvez viene a coincidir con el momento de máximo esplendor de la platería antequerana y, por consiguiente, con el nacimiento de su propia congregación, finalizando así la disputa con la malagueña. Esta institución, creada dentro del debate de cierre de las organizaciones gremiales españolas, se mantuvo hasta 1833. Durante sus primeros veinte años, la familia Gálvez poseyó en ella los puestos de máxima autoridad como el cargo de Hermano Mayor o secretario de la corporación, favoreciendo con ello la integración de otros miembros de la familia, como se ha podido observar para el caso de José de Gálvez y Calo.

En definitiva, la familia como célula básica de integración social también realizó la misma función en el terreno laboral, la pertenencia a un linaje concreto abrió caminos laborales que comenzaban en el momento mismo del aprendizaje. Las dificultades atravesadas por aprendices radicados en casas ajenas fruto de los abusos de poder fueron paliadas si estas relaciones maestro-aprendiz se daban con individuos que compartían uno de los elementos más preciados en los tiempos modernos: la sangre, y más si esta era limpia.

\section{BIBLIOGRAFÍA}

Alexandre, C. y Ruggiu, F. J., "La circulación de los oficios en Charleville. Familia y trabajo en los siglos XVIII y XIX", Revista de Historia Moderna, 34 (2016), pp. 239-256.

Barroso Vázquez, M. D., "Los plateros portuenses: análisis de su organización corporativa", Revista de Historia de El Puerto, 4 (1990), pp. 55-66.

Benavides Murillo, C., "Reflexiones sobre la formación y función social de los artesanos de Cartago en el siglo XVIII", Revista Estudios, 18-19 (2004-2005), pp. 15-28. 
Birriel Salcedo, M., "El cónyuge supérstite en el derecho hispano", Chronica Nova, 34 (2008), pp. 13-44.

Burgos Rincón, J., "Gremio, familia artesana y propiedad. Libreros e impresores en la Barcelona del siglo XVIII", en Familia, casa y trabajo, Murcia, Universidad, 1997, pp. 423444.

Chacón Jiménez, F. y Ferrer i Alós, L. "Más allá de la familia", Familia, casa y trabajo, Murcia, Universidad, 1997, pp. 13-16.

Chacón Jiménez, F., "Familia, casa y hogar. Una aproximación a la definición y realidad de la organización social española (siglos XVIII-XIX)", Espacios sociales, universos familiares. La familia en la historiografía española, Murcia, Universidad, 2007, pp. 51-68.

Colón de Larraeátegui, J., Tiempos de reforma ilustrada. Informe sobre los gremios de VaIladolid, Valladolid, Ayuntamiento, 2008 (ed. L. Amigo Vázquez, M. García Fernández y R. Hernández García).

Cruz Valdovinos, J. M. y Nieva Soto, P., "Los Morenos, una familia de plateros madrileña en el Antiguo Régimen", Anales del Instituto de Estudios Madrileños, 44 (2004), pp. 331-358.

Cruz Valdovinos, J. M., Catálogo de platería, Madrid, Ministerio de Cultura, 1982.

Cruz Valdovinos, J. M., Los plateros madrileños: estudio histórico-jurídico de su Organización Corporativa, Tomo I, Madrid, Gremio de Joyeros y Plateros de Madrid, 1993.

Diego Velasco, T. de, Los gremios granadinos a través de sus ordenanzas, Madrid, Universidad Complutense de Madrid, 1986.

Domínguez Ortiz, A., Sociedad y estado en el siglo XVIII español, Barcelona, Ariel, 1976.

Fernández Guirao, F. J., "Los Laborda, una familia de plateros entre los siglos XVIII-XIX", CLAVIS, 9 (2016), pp. 77-102.

Fernández Pérez, P. y Sola-Corbacho, J. C., "Familia y comerciantes en la España del Antiguo Régimen", en Espacios sociales, universos familiares. La familia en la historiografía española, Murcia, Universidad de Murcia, 2007, pp. 177-191.

Frey, D. A., "Industrious Households: servival strategies of artisans in a Sothwest German town during the eighteenth an early nineteenth centuries", International Review of Social History, 45 (2000), pp. 115-135.

García Abellán, J., Organización de los gremios en la Murcia del siglo XVIII y recopilación de ordenanzas, Murcia, Academia Alfonso X el Sabio, 1976.

García González, F. y Crespo Sánchez, F. J., "Radiografía de un impulso compartido. La historia de la familia en España e Iberoamérica (2000-2015)", en Familias en el Viejo y el Nuevo Mundo, La Plata, Universidad Nacional de La Plata, 2017, pp. 44-78.

García González, F., "Las estructuras familiares y su relación con los recursos humanos y económicos", en Familias. Historia de la sociedad española (del final de la Edad Media a nuestros días), Madrid, Cátedra, 2011, pp. 159-254.

García González, F., "Vejez, viudedad y soledad rural. Viudas, hogares y prácticas familiares en la España centro-meridional del siglo XVIII", Studia historica. Historia moderna, vol. 38, 2 (2016), pp. 287-324.

García González, F., Las estrategias de la diferencia. Familia y reproducción social en la Sierra (Alcaraz, siglo XVIII), Madrid, Ministerio de Agricultura, Pesca y Alimentación, 2000.

González Barrero, N., "Los maestros de primeras letras en la provincia de Madrid a través del Catastro de Ensenada", Historia y Memoria de la Educación, 3 (2016), pp. 197228.

González Enciso, A., "los gremios y el crecimiento económico”, Memoria y Civilización, 1 (1998), pp. 111-137. 
Guerra Guerra, A., "Profesionales, obreros y artesanos de Badajoz en 1750: sus ganancias y emolumentos según el Catastro de Ensenada", Revista de estudio extremeños, vol. 27, 3 (1971), pp. 561-582.

Gutiérrez Nieto, F. J. y Ybañez Worboys, P., "El Ilamamiento a la nobleza de las «dos Andalucías» de 1706", Revista de Historia Moderna, 25 (2007), pp. 53-87.

Hernández Benítez, M., A la sombra de la Corona. Poder local y oligarquía urbana (Madrid, 1606-1808), Madrid, Siglo XXI, 1995.

Hernández Franco, J. y Molina Puche, S., "La sangre de la familia y su proceso socioinstitucional. Siglos XVI-XVII" en Familias. Historia de la sociedad española (del final de la Edad Media a nuestros días), Madrid, Cátedra, 2011, pp. 113-156.

Hernández García, R., "Gremios y corporaciones laborales. Debate historiográficos y estado de la cuestión", Areas, (34 (2015), pp. 7-18.

Hernández López, C., "Trabajo y curso de vida. Los artesanos de Albacete (1636-1792)", en Escenarios de familia: trayectorias, estrategias y pautas culturales, siglo XVI-XX, Murcia, Universidad, 2017, pp. 257-269.

Herraéz Ortega, M. V., "Los Bello, platero de Sahagún, y las cruces procesionales de Vallecillo y Joarilla de las Matas (León)", en Estudios de Platería: San Eloy, Murcia, Universidad, 2002, pp. 183-194.

Irigoyen López, A. "Un obispado para la familia: Francisco Verdín Molina, prelado de Guadalajara y Valladolid en la segunda mitad del siglo XVII", Historia mexicana, vol. 58, 2 (2008), pp. 557-594.

Irigoyen López, A., "Bajo el manto de la Iglesia. Clero y familia en España durante la Edad Moderna", en Espacios sociales, universos familiares. La familia en la historiografía española, Murcia, Universidad de Murcia, 2007, pp. 245-269.

Llordén, A., "Noticas históricas de los maestros plateros antequeranos, siglos XVIII-XIX", Jábega, (8 (1974), pp. 81-92.

Mallo, J., "Emociones, honra y familia. Comerciantes españoles a finales del siglo XVIII", en Familias en el Viejo y el Nuevo Mundo, La Plata, Universidad Nacional de La Plata, 2017, pp. 367-385.

Marchant Rivera, A., "El prohijamiento, la tutela y la carta de aprendiz: instrumentos para una historia de la situación del menor en Málaga durante la primera mitad del siglo XVI", en Población y grupos sociales en el Antiguo Régimen, vol. 2, Málaga, Área de Historia Moderna de la Universidad de Málaga, 2009, pp. 943-956.

Miralles Martínez, P., Seda, trabajo y sociedad en la Murcia del siglo XVII, Murcia, Universidad, 2000.

Moral Roncal, A. M. Gremios e Ilustración en Madrid, (1775-1836), Madrid, Actas, 1998.

Moral Roncal, A. M., "Honor, vileza y honra de los oficios mecánicos en el siglo XVIII", Baetica, 18 (1996), pp.

Morgado García, A. J., "El ciclo vital de los esclavos en el Cádiz de la modernidad", Revista de historia moderna: Anales de la Universidad de Alicante, 34 (2016), pp. 297-315.

Morgado García, A. J., "La vida familiar de los esclavos en el Cádiz de la modernidad (16001750)", Trocadero: revista de historia moderna y contemporánea, 24 (2012), pp. 67-81.

Narotzky, S., "La renta del afecto: ideología y reproducción en el cuidado de los viejos", en Antropología de los pueblos de España, Madrid, Taurus, 1991, pp. 464-474.

Nieto Sánchez, J. A. y Zofío Llorente, J. C., "Los gremios de Madrid durante la Edad Moderna: una revisión", Áreas, 34 (2015), pp. 47-61.

Nieto Sánchez, J. A., Artesanos y mercaderes: una historia social y económica de Madrid, 1450-1850, Madrid, Fundamentos, 2006.

Ortega López, M., "Las edades de las mujeres", en Historia de las mujeres en España y 
América Latina, vol. 2, Madrid, Cátedra, 2005, pp. 317-350.

Pérez Samper, M. A., "Espacios y prácticas de sociabilidad en el siglo XVIII: tertulias, refrescos y cafés de Barcelona", Cuadernos de Historia Moderna, 26 (2001), pp. 1155.

Sánchez-Lafuente Gémar, R., "El Colegio-Congregación de plateros de Antequera (17821833)", Boletín de Arte, 12 (1991), pp. 317-336.

Sánchez-Lafuente Gémar, R., "La platería de Málaga en el siglo XVIII", en Estudios de Platería: San Eloy, Murcia, Universidad, 2001, pp. 241-256.

Sánchez-Lafuente Gémar, R., El Arte de Platería en Málaga, 1550-1800, Málaga, Universidad, 1997.

Zofío Llorente, J. C., Gremios y artesanos en Madrid, 1550-1650: la sociedad del trabajo en una ciudad cortesana preindustrial, Madrid, Instituto de Estudio Madrileños, 2005. 